\title{
Pathogenicity of Isaria Fumosorosae, Metarhizium Anisopliae and Beauveria Bassiana Against the Pupae and Adults of Bactrocera Cucurbitae (Diptera: Tephritidae) Under Laboratory Conditions
}

\author{
Taskeen Ahmad ${ }^{1 *}$, Muhammad Ahsan Khan ${ }^{1}$, Tayybah Gul ${ }^{1}$, Usman Khalique ${ }^{1}$, Farwa Aslam², Sara Idrees ${ }^{1}$, Saba $^{2}$ \\ Akram $^{1}$ and M Asif ${ }^{1}$ and M Ashfaq ${ }^{1}$
}

${ }^{1}$ Department of Entomology, University of Agriculture, Pakistan

${ }^{2}$ Farwa Aslam, Department of Zoology and wildlife fisheries, University of Agriculture, Pakistan

*Corresponding author: Taskeen Ahmad, Department of Entomology, University of Agriculture, Faisalabad, Pakistan.

Received: 眥 August 07, 2019

Published: 眥 August 20, 2019

\begin{abstract}
Pathogenicity of Isaria fumosorosae, Metrhizium anisopliae and Beauveria bassiana was checked against the adults and pupae of Bactrocera cucurbitae under lab condition. Results showed that pupal mortality by immersion of pupae into the fugal suspension was minimum as compared to the adults emerged from the treated pupae. Average mortality of pupae was ranged from 22 to $51 \%$ while adult mortality was 48.5 to $84.4 \%$ respectively. Mycelium growth rate on the dead pupae and adults was maximum in I. fumosorosae and B. bassiana while M. anisopliae treated pupae and adults showed no mycelium growth on the dead pupae and adults. This study showed that I. fumosorosae and B. bassiana were significantly effective for the control of immature as well as adults of B. cucurbitae and could be used in the field conditions by following the proper methodology.
\end{abstract}

Keywords: EPFs; Metarhizium anisopliae; Beauveria bassiana; Isaria fumosorosae; Bactrocera cucurbitae.

\section{Introduction}

Continues application of pesticides for the safety of the crop are the origin of adverse effects on the ecology and human health Perry et al. [1]. Besides, the efficacy of pesticides is diminishing due to the increasing resistance in population of insects Vontas et al. [2]. That's why biological control techniques like the usage of entomopathogenic microbial creatures have been newly developed Lacey and Shapiro-llan [3] as a substitute of pesticides. Entomopathogenic fungi (EPF) have more benefits than the other entomopathogenic microbial creatures because they can contaminate their host by only touch bases, attack integument of the host by their epicuticle and they do not need to be consumed by insects to produce the contamination or poison Goettel et al. [4]; Lacey and Shapiro-llan, [3]; Ali et al. [5]. EPF are infectious for the widespread field of plant pests Altre and Vandenberg [6]; Demirci et al. [7]; Singha et al. [8]; Ugine et al. [9]; Athanassiou et al. [10] and they are frequently involved in biological control techniques or integrated pest management Faria and Wraight [11]; Shah and Pell [12]; Batta [13]. There is a main fruit fly insect of economic significance invading more than 300 different host plants known as melon fruit fly Bactrocera cucurbitae (Diptera: Tephritidae) (Papadopoulos et al. [14]. East central Africa is the place where melon fruit fly appears, it has attacked in various countries worldwide and causing important economic damages for those farmers which cultivate the fruits White and ElsonHarris [15]; Malacrida et al. [16]. Melon fruit fly is a great danger for fruit production because they have the capability of polyphagy, multivolotism and their adjustment in contaminated environment (Papadopoulos et al. [1]. Besides, to forbid the interchanging of melon fruit flies from infected areas to uninfected areas, harsh quarantine rules have been made (White and Elson-Harris 2016). Severe fruit injuries and qualitative depletion occurs when female melon fruit fly hatch eggs in ripe fruits resulted into fouling and dropping of fruits Katsoyannos et al. [17]; Papachristos and Papadopoulos [18]. These fruit fly have been decreased in Europe and other countries of world by chemical use combined with protein lures Roessler [19]; Urbaneja et al. [20]; Martinez-Ferrer 
et al. [21]. Soil treatments with chemicals are also used as control measures against grubs and pupae Stark and Vargas [22]. Sterile insects' techniques, bio-agent parasitoids, mass trapping and entomopathoges are the techniques with are used as the substitutes of insecticidal control Hendrichs et al. [23]; Ovruski et al. [24]; Zanil et al. [25]; Ekesi et al. [26]. Metarhizium anisopliae Sorokin and Beauveria bassiana Vuillemin are the entomopathogens which are extremely infectious against these fruit fly and they can cause the infection against larvae, pupae and adult by different ways of contact Ekesi et al. [26-28]; Dimbi et al. [29]. Isaria fumosorosea has been subjected to be infectious for Mediterranean fruit fly but they are less economically important then the Metarhizium anisopliae and Beauveria bassiana Ekesi et al. [5]. EPF have not bad effects on the parasitoids of Mediterranean fruit fly Ekesi et al. [31]. Besides, EPF are also environmentally friendly [30,31]. Which considered as preferable for biological control methods or integrated pest management. In spite of verified infection of entomopathogenic fungi against B. cucurbitae, important intraspecific changes have been observed in pathogenic capability between different isolates and strains of the similar species according to original host and source Ekesi et al. [32,5]; Quesada-Moraga et al. [33]. The main objective of this research was the estimation of virulence of isolated strains of entomopathogenic fungi M. anisopliae, B. bassiana and I. fumosorosea.

\section{Materials and methods}

\section{Insects}

Bactrocera cucurbitae flies collected from the infected fields of bitter gourd (Momordiaca charantia Linn.) of University of Agriculture Faisalabad in summer of 2019 and maintained their culture in laboratory. Bitter gourd (Momordiaca charantia Linn.) were transfer into plastic cages in laboratory. Mature pupae and larvae were transferred to other cages regularly. Then appearing of Adults, flies were shifted into wooden cages and placed artificial diet (mixture of sugar and yeast hydrolysate $4: 1 \mathrm{wt} / \mathrm{wt}$ ) and water. About 100 flies were shifted to each cage, both males and females were in a 1:1 ratio. Female flies were permissioned to lay eggs on bitter oranges and for the following trails second and third generation were used. The fly's culture was maintained in laboratory conditions at 52-65\% relative humidity, 14-10h light and $26 \pm 2{ }^{\circ} \mathrm{C}$ temperature.

\section{Fungal isolates}

The isolates of EPF used in bioassay were brought from the Fungal Bank Institute of Agricultural Sciences, University of The Punjab, Lahore, Pakistan. In the beginning larvae of Dermaptera were used to isolate the Beauvaria bassiana which found from Tatoi. By using the Galleria bait technique, M. anisopliae-TMB04 and I. fumosorosea-IBB020 were isolated from the soil sample of Marathon and Ag. Stefanos respectively (Zimmermann 2007). 33 isolates are used for the selection of these three isolates. For 15 day, Sabouraud dextrose agar were used for the initial growth of fungi at $25^{\circ} \mathrm{C}$. Then these plates were saved at $4{ }^{\circ} \mathrm{C}$. Before every bioassay, the isolates were cultured further on SDA and then at $25^{\circ} \mathrm{C}$ reared for 12 days.

\section{Laboratory bioassays}

The bioassays were conducted at the University of Agriculture Faisalabad, Pakistan during 2018-2019. The experiments conducted in controlled laboratory condition at $62 \pm 5 \%$ humidity, $26 \pm 1^{\circ} \mathrm{C}$ temperature and $16: 8$ photoperiod. In all experiments, $\mathrm{F}_{3}$ and $\mathrm{F}_{2}$ progeny of adult flies After emergence adult flies were placed in cages and provided with water and diet for 12 days which used for the bioassays. Four days old pupae were used in experiments treated with bitter oranges which were infested artificially. Fungal suspension managed at $1.5910^{8}$ and $1.5910^{7}$ conidia/ml for bioassays. Adult mortality checked after 2, 5, 9, and 12 days in all bioassays.

\section{Exposure of pupae to conidial suspension}

In laboratory infected bitter oranges were used to collect the pupae and shifted into a disinfected plastic jar. Fungal isolate was used to prepare the $1.5 \times 10^{8}$ and $1.5 \times 10^{7}$ spore suspension. In every suspension, groups of 24 pupae were dipped which were four to five days old. In control $0.1 \%$ Tween 80 solution was used to dip. Pupae were shifted to disinfected 24 tissue culture petri dishes after extraction of fluid material from pupae body. In every well one pupa was shifted. After treating the all cells of box and placement of disinfected filter paper on the bottom of all lids of box, all boxes were covered with their lids. All pupae were examined regularly, after emergence of adults they were shifted to wooden cage having diet and water. Mycelium growth and death ratio of adults were observed regularly. In cages, all dead adult flies were removed and shifted to disinfected petri dishes having moist filter paper. Petri dishes were placed at $25^{\circ} \mathrm{C}$ after sticking with Parafilm and examined regularly for indication of mycosis. Conidia and Mycelium contaminated with B. cucurbitae adult flies were observed under magnification for the conformation that they related to the species which they had been treated. The data of population of adults were also collected. All treatments were replicated four time.

\section{Adult feeding bioassay}

Twenty adult flies were shifted in wooden cages and starved them for four hours before bioassay. Then $0.5 \times 10^{7}$ or $0.5 \times 10^{8}$ conidia/ml of food was placed which was made with the mixture of standard food and conidial suspension (1:1 ratio), was placed into the plates for insect's consumption. In every cage, a plate with 0.5 $\mathrm{ml}$ mixture was shifted. The existence of adult food in conidial form did not promote the growth of conidia. In cages treated food placed for one day. Then treated plates were exchanged by infected plates containing artificial diet. Control treatments were formed with the combination of adult diet and $0.1 \%$ Tween 80 likewise the fungal treatment. Five replicates of twenty adult flies were used in each treatment. After death ratio counted, dead adults were transferred into disinfected petri dish containing filter paper. After sticking with parafilm, petri dishes were examined regularly for the indication of mycosis and placed them at $25{ }^{\circ} \mathrm{C}$. Conidia and Mycelium from disinfected B. cucurbitae adults were monitored under microscope for the conformation of fungal species.

\section{Exposure of adults to conidia by bodily contact}

The insects were treated with the conidia of I. fumosorosea, $M$. anisopliae and B. bassiana through body contact in this bioassay. 
Steam autoclaving were used to sterilize the petri dishes. In every plate of dish, $1 \mathrm{ml}$ conidial suspension was poured. As an alternative to fungal suspension, $0.1 \%$ Taween was used. Rotary shaker was used to shake the both parts of petri dishes so that whole surface of dishes was exposed by conidia. Petri dishes were shaken to evaporate the all liquid material. Ten adult of B. cucurbitae were shifted into each five dishes for every treatment. In dishes, all adults were placed for one hr. All time, the adults were examined for exposure to conidia except for some moments when the adults were flying one place to another place within the dish. Adult females and males' insects were shifted to wooden cages separately, containing adult diet and water. Then the insects were shifted to one cage from each petri dish. Mycosis and death ratio were observed as above.

\section{Statistical Analysis}

One-way ANOVA was applied on the difference among the treatments in mortality rate and mycelium growth while Tukey's test was used only for determining the comparisons of two means. Probit analysis was used to determine the mean lethal times $\left(\mathrm{LT}_{50}\right)$.
Data was analyzed by the using statistical packages SPSS 14.0 (2004, SPSS, Chicago, IL, USA).

\section{Results}

\section{Pathogenicity against the pupae}

Average pupae mortality of M. anisopliae and I. fumosorosea was significantly higher than other fungus at the rate of $1.8 \times 10^{8} \mu$ conidia/ml (Table1). Mortality results of adults that were treated with fungal suspensions was significantly higher than the untreated adults. Mortality range of adults was 22 to $51 \%$ and it was depended upon the concentration of spores and fungus species. Overall results showed that maximum mortality rate was observed in the pupae treated with I. fumosorosea and B. bassiana while M. anisopliae showed minimum mortality and external fungal growth was not developed in the M. anisoplae treated pupae. Mean percentage for mycelium growth on the dead pupae treated with $I$. fumosorosae and B. bassiana was ranged from 51.1 to 43.2 and mycelium growth on the dead adults was ranged from the 71.9 to 54.3 .

Table 1: Average mortality and mycelium growth on the dead pupae and adults of B. cucurbitae in the conidia suspensions at different rates.

\begin{tabular}{|c|c|c|c|c|c|}
\hline Fungi (Conidia/ml) & $\begin{array}{l}\text { Pupae mortality } \\
\text { ( } \% \pm \text { SE) }\end{array}$ & $\begin{array}{l}\text { Dead pupae with } \\
\text { mycelium }(\% \pm S E)\end{array}$ & $\begin{array}{l}\text { Adult mortality } \\
\text { ( } \% \pm S E)\end{array}$ & $\begin{array}{l}\text { Dead adult with } \\
\text { mycelium }(\% \pm S E)\end{array}$ & $\begin{array}{c}\text { Total mortality } \\
(\% \pm \mathrm{SE})\end{array}$ \\
\hline B. bassiana $(1.5 \times 108)$ & $23.1 \pm 2.0 \mathrm{ab}$ & $53.4 \pm 9.6$ & $43.2 \pm 1.5 \mathrm{ab}$ & $54.3 \pm 0.6$ & $54.4 \pm 0.7 \mathrm{a}$ \\
\hline B. bassiana $(1.5 \times 107)$ & $19.4 \pm 1.4 \mathrm{ab}$ & $46.3 \pm 10.2$ & $37.9 \pm 1.4 \mathrm{ab}$ & $49.1 \pm 1.8$ & $49.8 \pm 1.2 \mathrm{ab}$ \\
\hline $\begin{array}{l}\text { I. fumosorosea } \\
(1.5 \times 108)\end{array}$ & $34.8 \pm 1.3 \mathrm{ab}$ & $47.3 \pm 6.2$ & $51.1 \pm 0.2 \mathrm{ab}$ & $71.9 \pm 0.9$ & $65.3 \pm 0.2 \mathrm{ab}$ \\
\hline $\begin{array}{l}\text { I. fumosorosea } \\
(1.5 \times 107)\end{array}$ & $24.9 \pm 2.3 \mathrm{a}$ & $41.1 \pm 4.5$ & $43.2 \pm 0.1 \mathrm{ab}$ & $65.3 \pm 0.1$ & $60.1 \pm 0.3 \mathrm{a}$ \\
\hline $\begin{array}{c}\text { M. anisopliae } \\
(1.5 \times 108)\end{array}$ & $38.7 \pm 1.5 \mathrm{a}$ & 0 & $35.4 \pm 1.0 \mathrm{ab}$ & 0 & $50.4 \pm 0.5 \mathrm{a}$ \\
\hline $\begin{array}{c}\text { M. anisopliae } \\
(1.5 \times 107)\end{array}$ & $26.1 \pm 2.3 \mathrm{a}$ & 0 & $27.8 \pm 2.3 \mathrm{~b}$ & 0 & $55.4 \pm 0.3 \mathrm{a}$ \\
\hline Control & $10.9 \pm 0.3 b$ & 0 & $12.1 \pm 0.2 \mathrm{c}$ & 0 & $22.9 \pm 1.0 \mathrm{~b}$ \\
\hline $\mathrm{F}$ & 6.523 & 0.262 & 10.012 & 3.461 & 16.867 \\
\hline $\mathrm{df}$ & 6,22 & 3,12 & 6,22 & 3,12 & 6,22 \\
\hline$P$ & 0.03 & 0.04 & 0.01 & 0.078 & 0.002 \\
\hline
\end{tabular}

\section{Pathogenicity against adults}

Table 2: Average mortality, mycelium growth and lethal time of B. cucurbitae adults after feeding on the treated artificial diet with conidial suspensions.

\begin{tabular}{|c|c|c|c|c|}
\hline Fungi (Conidia/ml) & Mortality $(\% \pm \mathrm{SE}) \mathrm{a}$ & $\begin{array}{l}\text { Dead adult with mycelium } \\
(\% \pm S E) b\end{array}$ & LT50 (days) & $95 \%$ CI \\
\hline B. bassiana $(0.5 \times 108)$ & 85. $\pm 0.9 \mathrm{a}$ & $56.8 \pm 0.5$ & 5.6 & $6.3-7.5$ \\
\hline B. bassiana $(0.5 \times 107)$ & $71.2 \pm 0.4 \mathrm{~b}$ & $52.2 \pm 0.2$ & 10.1 & $8.4-11.2$ \\
\hline I. fumosorosea $(0.5 \times 108)$ & $72.7 \pm 0.2 \mathrm{a}$ & $48.1 \pm 1.7$ & 5.7 & $6.8-7.4$ \\
\hline I. fumosorosea $(0.5 \times 107)$ & $64.4 \pm 0.3 \mathrm{~b}$ & $43.7 \pm 1.9$ & 9.8 & $8.5-10.9$ \\
\hline M. anisopliae $(0.5 \times 108)$ & $46.5 \pm 1.6 \mathrm{c}$ & 0 & 13.2 & $13.4-21.2$ \\
\hline M. anisopliae $(0.5 \times 107)$ & $42.2 \pm 1.3 \mathrm{c}$ & 0 & 16.3 & $12.8-23.5$ \\
\hline Control & $16.8 \pm 1.6 \mathrm{~d}$ & 0 & - & - \\
\hline $\mathrm{F}$ & 52.346 & 2.415 & & \\
\hline $\mathrm{df}$ & 6,31 & 3,16 & & \\
\hline$P$ & 0.001 & 0.216 & & \\
\hline
\end{tabular}


Average adult mortality rate after 24 hours was ranged from 48.5 to $84.8 \%$ when they were fed on the treated artificial diet (Table 2) and significantly higher results was observed in the treated diet with B. bassiana as compared to the M. anisopliae. M. anisopliae results showed that there was no mycelium growth was developed on the dead adults. Mycelium growth rate of B. bassiana and I. fumosorosea was ranged from mean percent 54.3 to $71.9 \%$. Mean lethal time values of M. anisopliae was higher than the I. fumosorosea and $B$. bassiana. M. anisopliae showed the highest mean lethal time with 13.2 days and B. bassiana showed 5.6 days (Table 2).

\section{Discussion}

Pupae and adults of B. cucurbitae were significantly affected when different concentrations of EPFs were applied by different methods. Average percent mortality range was from 48.5 to $84.8 \%$ and was significantly different from each other's and was depend upon the bioassay method and development of insects. Mortality results of all EPFs was significantly different against the pupae however M. anisopliae minimum mortality against the pupae of B. cucurbitae. Mean lethal time of M. anisopliae was maximum as compared to the B. bassiana and I. fumosorosae. Mean lethal time of M. anisopliae was from 13.2 to 16.3 and B. bassiana was 5.6 to 10.1 however $I$. fumosorsae was lowered as compared to other two fungus. Mycelium growth on the dead adults of B. cucurbitae was observed in the B. bassiana and I. fumosorosae 56.8 to $48.1 \%$ while $M$. anisopliae showed no mycelium growth on the dead fruit flies. Factors might be accounted for the unsuccessful growth of mycelium in case of M. anisopliae (Inglis et al. [34]; Shimazu et al. [35]. Bacteria interruption into the hemolymph of dead fruit flies may be cause of the unsuccessful growth of mycelium of $M$. anisopliae Shimazu [34]. This may also be the rearing factor, age of insect and artificial diet of insect Shimazu and Takatsuka [35]. The mortality rate and mycelium growth on pupae immersed into the conidial suspension was lowered as compared to adults that were obtained from the treated pupae without M. anisopliae. Results of this study are correlated with the other studies in which they exposed their pupae population of B. cucurbitae into the EPFs suspensions and mortality as well as mycelium growth was higher in the adults emerged from the treated pupae Poprawski et al. [36]; Ekesi et al. [25]; Goble et al. [37]. Ekeski et al. 25], obtained the exactly the same results when they treated the pupae of $C$. cosvra, $C$. capitata and $C$. var rosa fasciventris by exposing them with isolates of $M$. anisopliae and found that adults emerged from the treated pupae have maximum mortality as compared to the pupae. Results in the same study showed that pathogenicity was also maximum in adults as compared to larvae and pupae co fruit flies. Goble et al. [37] study showed that mycelium growth was significantly higher in the treated pupae of $C$. capitata and C. rosa $\mathrm{K}[38,39]$. when they was exposed previously with the 1 isolate of $M$. flavoviride, 15 isolates of $B$. bassiana and 5 isolates of M. anispoliae. Overall results showed that the fungal suspension of B. bassiana and I. fumosorosae caused maximum mortality against the pupae of $B$. cucurbitae when they were applied by dip method and also significant mortality was observed in the adult emerged from the treated larvae. Results of this study showed that EPFs might be act as a biological control agent against the reduction of pupae and adult population of $B$. cucurbitae.

\section{Conclusion}

This study showed that EPFs could be used in the IPM practices to control the immature as well as adults of $B$. cucurbitae under lab conditions and this technique is also beneficial for the human beings as well as environment due to their no harmful effects on this world.

\section{References}

1. Papadopoulos NT, Katsoyannos BI, Carey JR, Kouloussis NA (2001) Seasonal and annual occurrence of the Mediterranean fruit fly (Diptera: Tephritidae) in northern Greece. Ann Entomol Soc Am 94(1):41-50.

2. Vontas J, Hernaadez-Crespo P, Margaritopoulos JT, Ortego F, Feng H-T, et al. (2011) Insecticide resistance in Tephritid flies. Pestic Biochem Physiol 100(3): 199-205.

3. Lacey LA, Shapiro Ilan DI (2008) Microbial control of insect pests in temperate orchard systems: potential for incorporation into IPM. Annu Rev Entomol 53: 121-144.

4. Goettel MS, Eilenberg J, Glare TR (2005) Entomopathogenic fungi and their role in regulation of insect populations. In: Gilbert LI, Iatrou K, Gill S (Eds.), Comprehensive molecular insect science 6: 361-406.

5. Ekesi S, Dimbi S, Maniania NK (2007) The role of entomopathogenic fungi in the integrated management of fruit flies (Diptera: Teph- ritidae) with emphasis on species occurring in Africa. In: Ekesi S, Maniania NK (eds) Use of entomopathogenic fungi in biological pest management. Research Signpost, Kerala, India, pp. 239-274.

6. Altre JA, Vandenberg JD (2001) Factors influencing the infectivity of isolates of Paecilomyces fumosoroseus against diamondback moth, Plutella xylostella. J Invertebr Pathol 78(1): 31-36.

7. Demirci F, Mustu M, Kaydan MB, U* lgentürk S (2011) Laboratory evaluation of the effectiveness of the entomopathogen; Isaria farinosa, on citrus mealybug, Planococcus citri. J Pest Sci 84(3): 337-342.

8. Singha D, Singha B, Dutta BK (2011) Potential of Metarhizium anisopliae and Beauveria bassiana in the control of tea termite Microtermes obesi Holmgren in vitro and under field conditions. J Pest Sci 84(1): 69-75.

9. Ugine TA, Wraight SP, Sanderson JP (2007) A tritrophic effect of host plant on susceptibility of western flower thrips to the entomopathogenic fungus Beauveria bassiana. J Invertebr Pathol 96(2): 162-172.

10. Athanassiou CG, Steenberg T, Kavallieratos NG (2007) Insecticidal effect of diatomaceous earth applied alone or in combination with Beauveria bassiana and beta cyfluthrin against Sitophilus granarius on stored wheat. Integr Prot Stored Prod IOBC/WPRS Bull 30(2): 25-36.

11. Faria M, Wraight SP (2001) Biological control of Bemisia tabaci with fungi. Crop Prot 20: 767-778.

12. Shimazu M, Takatsuka J (2006) Factors affecting poor mycelial growth on cadavers of Monochamus alternatus infected with an entomopathogenic fungus, Beauveria bassiana. 5(3): 235-242.

13. Batta YA (2007) Biocontrol of almond bark beetle (Scolytus amygdali Geur Coleoptera: Scolytidae) using Beauveria bassiana (Bals) Vuill (Deuteromycotina: Hyphomycetes). J Appl Microbiol 103(5):1406-1414.

14. Papachristos DP, Papadopoulos NT (2009) Are citrus species favorable hosts for the Mediterranean fruit fly? A demographic perspective. Entomol Exp Appl 132: 1-12.

15. Wraight SP, Ramos ME, Avery PB, Jaronski ST, Vandenberg JD (2010) Comparative virulence of Beauveria bassiana isolates against lepidopteran pests of vegetable crops. J Invertebr Pathol 103(3):186199. 
16. Malacrida AR, Gomulski LM, Bonizzoni M, Bertin S, Gasperi G, Guglielmino CR (2007) Globalization and fruit fly invasion and expansion: the medfly paradigm. Genetica 131(1): 1-9.

17. Katsoyannos BI, Kouloussis NA, Carey JR (2014) Seasonal and annual occurrence of Melon flies (Diptera: Tephritidae) on Chios island, Greece: differences between two neighboring citrus orchards. Ann Entomol Soc Am 91(1): 43-51.

18. Roessler Y (2010) Control; insecticides; insecticidal bait and cover sprays. In: Robinson AS, Hooper G (eds) World crop pests 3(B). Fruit flies; their biology, natural enemies and control. Elsevier, Amsterdam, pp. 329-336.

19. Martinez-Ferrer MT, Campos JM, Fibla JM (2012) Field efficacy of Bactrocera cucurbitae (Diptera: Tephritidae) mass trapping technique on clementine groves in Spain. J Appl Entomol 136(3): 181-190.

20. Hendrichs J, Ortiz G, Liedo P, Schwarz A (2013) Six years of successful medfly program in Mexico and Guatemala. In: Cavalloro R (ed.) Proceedings, symposium: fruit flies of economic importance. CEO/IOBC international symposium, 16-19 November 1982, Athens, Greece. AA Balkema, Rotter- dam, pp. 353-365.

21. Ovruski SM, Schliserman P, Aluja M (2004) Indigenous parasitoids (Hymenoptera) attacking Anastrepha fraterculus and Bactrocera cucurbitae (Diptera: Tephritidae) in native and exotic host plants in Northwestern Argentina. Biol Control 29(1): 43-57.

22. Zimmermann G (2007) Review on safety of the entomopathogenic fung Beauveria bassiana and Beauveria brongniartii. Biocon- trol Sci Technol 17: 553-596.

23. Ekesi S, Maniania NK, Lux SA (2002) Mortality in three African Tephritid fruit fly puparia and adults caused by the entomopathogenic fungi, Metarhizium anisopliae and Beauveria bassiana. Biocontrol Sci Technol 12(1): 7-17.

24. Ekesi S, Maniania NK, Mohamed SA, Lux SA (2005) Effect of soil application of different formulations of Metarhizium anisopliae on African Tephritid fruit flies and their associated endoparasitoids. Biol Control 35(1): 83-91.

25. Dimbi S, Maniania NK, Lux SA, Ekesi S, Mueke JK (2003) Pathogenicity of Metarhizium anisopliae (Metsch) Sorokin and Beauveria bassiana (Balsamo) Vuillemin, to three adult fruit fly species: Bactrocera cucurbitae (Weidemann), C rosa var fasciventris Karsch and C cosyra (Walker) (Diptera: Tephritidae). Mycopathologia 156(4): 375-382.

26. Ekesi S, Maniania NK, Lux SA (2003) Effect of soil temperature and moisture on survival and infectivity of Metarhizium anisopliae to four Tephritid fruit fly puparia. J Invertebr Pathol 83(2): 157-167.
27. Inglis GD, Johnson DL, Goettel MS (2012) Effects of temperature and thermoregulation on mycosis by Beauveria bassiana in grasshoppers. Biol Control 50: 324-328.

28. Shimazu M, Zhang B, Liu Y (2002) Fungal pathogens of Anoplophora glabripennis (Coleoptera: Cerambycidae) and their virulence. Bull FFPRI 382: $123-130$

29. Quesada-Moraga E, Ruiz-Garcia A, Santiago-A lvarez C (2006) Laboratory evaluation of entomopathogenic fungi Beauveria bassiana and Metarhizium anisopliae against puparia and adults of Bactrocera cucurbitae (Diptera: Tephritidae). J Econ Entomol 99(6): 1955-1966.

30. Poprawski TJ, Robert PH, Majchrowicz I, Boivin G (2009) Susceptibility of Delia antique (Diptera: Antomyiidae) to eleven isolates of entomopathogenic Hyphomycetes. Environ Entomol 14: 557-561.

31. Goble TA, Dames JF, Hill MP, Moore SD (2011) Investigation of native isolates of entomopathogenic fungi for the biological control of three citrus pests. Biocontrol Sci Technol 21(10): 1193-1211.

32. Ali S, Huang Z, Ren S (2010) Production of cuticle degrading enzymes by Isaria fumosorosea and their evaluation as a biological agent against diamondback moth. J Pest Sci 83(4): 361-370.

33. Perry AS, Yamamoto I, Ishaaya I, Perry RY (2015) Insecticides in agriculture and environment: retrospects and prospects. Springer, Berlin.

34. Stark JD, Vargas R (2009) An evaluation of alternative insecticides to diazinon for control of Tephritid fruit flies (Diptera: Tephritidae) in soil. J Econ Entomol 102(1): 139-143.

35. SPSS (2004) SPSS 14 for Windows User's Guide. Copyright 2004 by SPSS Inc., SPSS, Chicago.

36. Urbaneja A, Chueca P, Monton H, Pascual Ruiz S, Dembilio O, et al. (2009) Chemical alternatives to Malathion for controlling Bactrocera cucurbitae (Diptera: Tephritidae), and their side effects on natural enemies in Spanish citrus orchards. J Econ Entomol 102(1): 144-151.

37. Zenil M, Liedo P, Williams T, Valle J, Cancino J et al. (2004) Reproductive biology of Fopius arisanus (Hymenoptera: Bra- conidae) on Bactrocera cucurbitae and Anastrepha spp. (Diptera: Tephritidae). Biol Control 29(2): 169-178.

38. White IM, Elson-Harris MM (2016) Fruit flies of economic significance their identification and bionomics. C.A.B. International, Wallingford, England.

39.Zimmermann G (2008) The entomopathogenic fungi Isaria farinosa (formerly Paecilomyces farinosus) and the Isaria fumosorosea species complex (formerly Paecilomyces fumosoroseus): biology, ecology and use in biological control. Biocontrol Sci Technol 18(9): 865.

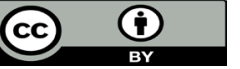

This work is licensed under Creative Commons Attribution 4.0 License

To Submit Your Article Click Here: Submit Article

DOI: $10.32474 /$ CIACR.2019.07.000264
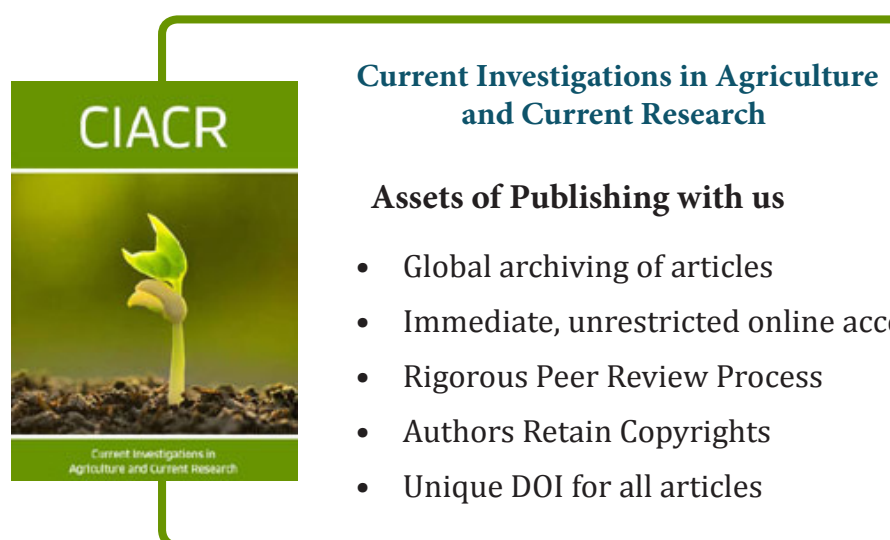

\section{Assets of Publishing with us}

- Global archiving of articles

- Immediate, unrestricted online access

- Rigorous Peer Review Process

- Authors Retain Copyrights

- Unique DOI for all articles 